\title{
Analysis of an energy storage sizing for grid-connected photovoltaic system
}

\author{
Aimie Nazmin Azmi, Norhafiz Salim, Aziah Khamis \\ Fakulti Kejuruteraan Elektrik, Centre for Robotics and Industrial Automation (CeRIA), \\ Univerisiti Teknikal Malaysia Melaka (UTeM), Malaysia
}

\section{Article Info \\ Article history: \\ Received Jan 3, 2019 \\ Revised May 4, 2019 \\ Accepted May 25, 2019 \\ Keywords: \\ Energy storage \\ Lead-acid battery \\ Lithium ion battery \\ Operating cost \\ Photovoltaic}

\begin{abstract}
This paper present on the analysis of an energy storage sizing for a small grid-connected PV system. This project is to study the proper sizing of energy storage (battery) in a grid-connected PV system for consumers whom purchase and sell electricity from and to the utility grid. The goal is to minimize the total cost of the operation for a consumer with a PV system with a battery storage system. This is to make sure that minimizing the total annual operating cost while maintaining an efficient system. This study uses typical consumer load consumption, and solar irradiance data throughout a year, while varying the type of battery storage (study lead acid and Lithium ion battery) as an energy storage for a similar system. Since lithium ion is not the main options to be integrated with PV system, this study will then reveal the data in terms of cost on why it is not a popular choice.
\end{abstract}

Copyright $@ 2019$ Institute of Advanced Engineering and Science. All rights reserved.

\section{Corresponding Author:}

Aimie Nazmin Azmi,

Fakulti Kejuruteraan Elektrik,

Universiti Teknikal Malaysia Melaka,

Hang Tuah Jaya, 76100, Durian Tunggal, Melaka, Malaysia.

Email: aimienazmin@utem.edu.my

\section{INTRODUCTION}

Renewable energy is common nowadays. REN21 report 2018 shows that annual investment in renewable rose up to 279.8 billion USD in 2017 compared to previous years [1]. This number is an increment form $2017 \mathrm{GW}$ to $2195 \mathrm{GW}$ of generation including hydro power. From this figure, $402 \mathrm{GW}$ is being generated by Solar PV. This makes PV solar continued to be the fastest growing power technology with a $70 \%$ increase in existing capacity from $13 \mathrm{GW}$ in 2008 to $303 \mathrm{GW}$ in 2016. This is an increment of more than $95 \%$ within 8 years [2]. The excitement of utilizing the PV solar hence restricted due to the disturbance of the solar waves caused by weather variations and grid power outages. This is where the energy storage is used as a backup in the system. Therefore, to have an efficient PV system, it is desirable to have properly sized energy storage [3].

Battery energy storage systems (BESS) is the most common energy storage that can be integrated into grid connected PV system. Battery is used to store energy when the PV power is not available. By adding battery storage to Grid-connected PV system, it will increase load consumption and reduce the dependence on the grid. A battery system must have the capacity to supply consistent power when the PV system is generating less power output. Since the battery is being made out of chemicals, the way of they utilized the battery will affect its performance, lifetime and cost. Having battery for energy storage in PV system means the power is guaranteed even in cloudy days. Thus, choosing the batteries in PV system have to meet the demand of the load. The requirement to choose the batteries includes cost, life-cycle, installation and services $[4,5]$.

With a multiple choice of battery in the market nowadays, this paper will be discussed specifically on the performance and sizing for Lithium-ion (Li-ion) and lead-acid battery. Li-ion battery is the most 
common energy storage that used for other few technologies (UPS, recreational vehicle power, etc.). It has 3 times higher energy density than the Lead acid battery and it can deliver more cycles in their lifetime than the Lead Acid battery. This will make Li-ion as the best choice for energy storage in PV system. Even the cost of Li-ion battery will be slightly higher, it still can make more profit after including the battery lifetime. In the year 2016, Li-ion battery is becoming more important in RE generation [6]. The ultimate advantage of Li-ion battery is higher charge and discharge rate. Thus, it will increase the product efficiency. Thus, it will be beneficial to compare the sizing of the Li-ion and lead acid battery. Based on the end results, it will be a significant reason to compare the same PV system with different type of battery [7].

To make the simulation looks appropriate with different grid price at different time. The Time-ofuse (TOU) data is used. Time of use or TOU is the isolation of energy rates based on time of the energy being consumed. TOU is a way for utility providers attempt to reduce demand during peak periods by enforcing tariff structures that impose an increased rate in typical peak period usage. In current years, the TOU tariff based on peak and off-peak pricing have become one of the most successful strategies to reduce load consumption during peak hour [8]. Basically, electric price during peak hour is higher than off-peak. The period of peak hour is set from 7 a.m. to 1 p.m. and 4 p.m. to 8 p.m. The implementation is to control consumer behaviour and to ease the energy usage needed most demand time. The consumer will try to use energy efficiently in order to avoid to pay higher electric bills.

The load data used in this paper is an operational load from an average small house with an area of $154 \mathrm{~m}^{2}$. The roof area is approximately less than $50 \mathrm{~m}^{2}$. The price data is taken from Pacific gas and electric company (San Francisco, California). There are a few key assumptions and limitations due to lack of data and the difficulties of collecting real data. Regarding the cost, the maintenance cost of the grid connected PV system with battery storage is assumed as zero. The author has fixed the installed sixe of PV on the house is $5 \mathrm{kWp}$ system and the tilting angle of the PV panel is ignored $[9,10]$.

\section{METHODOLGY}

To find the sizing of the energy storage, the simulation is run by using MATLAB software. The simulation starts by inserting PV data, electric price data and load consumption data, hence the data are crucial to be loaded into the MATLAB simulation.

\subsection{PV Data}

PV data is the detail information about the PV system. The data includes the PV system size data $(\mathrm{kW})$ and global irradiance data. The PV system size is assumed as $5 \mathrm{~kW}$ and installed at residence. The relevant size of PV panel is then calculated by using PV watts calculator of the National Renewable Energy Laboratory and the inputs. PV Watts Input as shown in Table 1.

The input power is $4.25 \mathrm{~kW} / \mathrm{m}^{2}$ based on annual calculated solar irradiance. Then, the approximate size of PV panel area suitable for this specific residence is $6.5 \mathrm{~m}^{2}$. Figure 1 shows the average PV output profile of the system throughout the year. The highest annual monthly average peak PV output is approximately $258.2403 \mathrm{~kW}$ in June. The average daily PV output is $20.69 \mathrm{kWh}$ which is $75 \%$ of the average daily energy consumption.

Table 1. PV Watts Input [11]

\begin{tabular}{cc}
\hline PV system size $(\mathrm{kW})$ & 5 \\
\hline Array type & Fixed-roof mount \\
DC to AC derate factor & 0.77 \\
Tilt angle $(\mathrm{deg})$ & 37.8 \\
Azimuth $(\mathrm{deg})$ & 180 \\
\hline
\end{tabular}

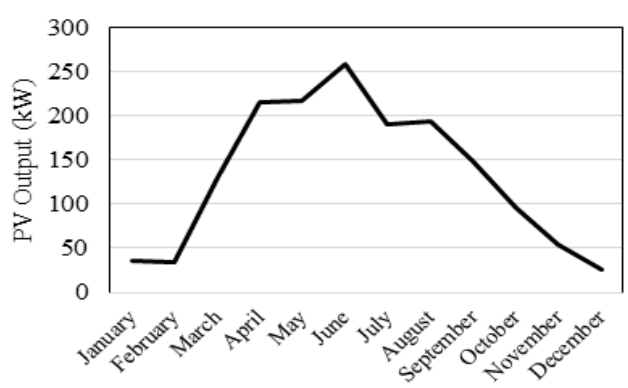

Figure 1. Average monthly PV output profile

\subsection{Electric Price Data}

Table 2 shows the electrical tariff rate depending on time of use (TOU) that will be used in this study. The purchase and export rate are equivalent. 
Table 2. Time of Use Rates

\begin{tabular}{ccccc}
\hline & \multicolumn{2}{c}{ Summer } & \multicolumn{2}{c}{ Winter } \\
& Peak hour & Off- Peak hour & Peak hour & Off- Peak hour \\
\hline Charge & 0.35146 & 0.10330 & 0.13695 & 0.10691 \\
\hline
\end{tabular}

This tariff price is a random price, but it is still based on an average energy price where they have a significant change for tariff during winter and summer. Then it is divided into off-peak and peak hours. This is not suitable for a country with no significant winter or no winter at all, e.g tropical country [12].

\subsection{Load Consumption Data}

The annual average daily consumption for the data is $27.315 \mathrm{kWh}$. Figure 2 shows average hourly load consumption data that been used in simulation. Base data is in hourly, and Figure 2 is plot based on average daily data. However, for the MATLAB simulation the actual hourly data is being used. This load data is based on an average house with a size of $154 \mathrm{~m}^{2}$ in a country with a significant winter and summer temperature.

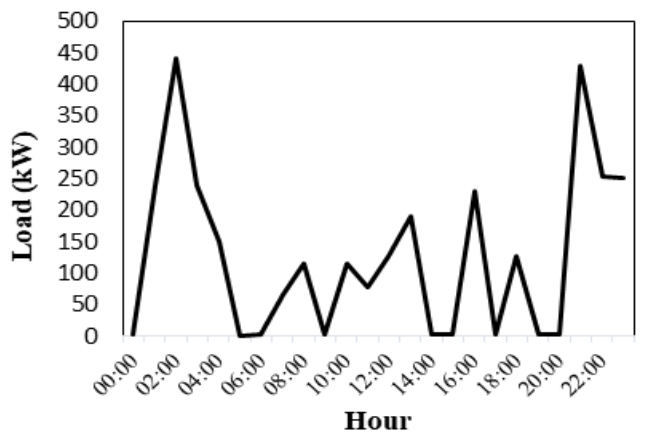

Figure 2. Average hourly load consumption data

\subsection{Battery Storage}

In this study, there are 2 types of battery that being simulated. Based on the simulation the most efficient and economical can be determined. The selected battery type are Lead-Acid battery and Li-ion battery. The specifications of Lead-acid battery are shown as in Table 3. This type of battery is considered as valve regulated lead acid (VRLA) deep cycle batteries $[13,14]$. This type of battery is mainly used for deep cycle with deep discharge applications like in sail boats and electrical vehicles.

For Li-ion battery, it is well known that this battery has 3 times higher energy density than the Lead acid battery. Because of that, this paper will analyse this and the conclusive result can be executed in the end. Specification of Li-ion battery that is used in the simulation is shown in Table $4[15,16]$.

Table 3. Specification of Lead-Acid Battery

\begin{tabular}{cc}
\hline Specification & Value \\
\hline Nominal Voltage & $12 \mathrm{~V}$ \\
Self-discharging factor & $5 \%$ per month \\
SOC min & $30 \%$ \\
SOC max & $90 \%$ \\
Min charging rate & 10 hours \\
Charge/Discharge efficiency & $90 \%$ \\
Battery inverter cost & $\$ 606$ \\
Lifetime of battery inverter & 10 years \\
Battery investment cost & $\$ 200$ \\
\hline
\end{tabular}

Table 4. Specification of Lithium-ion Battery [17-19]

\begin{tabular}{cc}
\hline Specification & Value \\
\hline Nominal Voltage & $12 \mathrm{~V}$ \\
Self-discharging factor & $2 \%$ per month \\
SOC min & $30 \%$ \\
SOC max & $90 \%$ \\
Min charging rate & 10 hours \\
Charge/Discharge efficiency & $96 \%$ \\
Battery inverter cost & $\$ 606$ \\
Lifetime of battery inverter & 10 years \\
Battery investment cost & $\$ 780$ \\
\hline
\end{tabular}

\section{SIMULATION}

Table 5 shows the input parameter that will be used in MATLAB files to determine the optimum size of the battery $[20,21]$. 


\begin{tabular}{lcc} 
Table 5. Input Parameter Values for MATLAB Optimization \\
\hline \multicolumn{1}{c}{ Variable } & Notation & Value \\
\hline Ageing coefficient & $\mathrm{Z}$ & $5 \times 10-4$ \\
Minimum state of charge & SOCmin & $30 \%$ \\
Maximum state of charge & SOCmax & $90 \%$ \\
Self-discharging factor & $\mathrm{a}$ & $2.5 \%$ per month \\
Minimum charging/discharging time & $t_{\text {min }}$ & 10 hours \\
PV inverter efficiency & $\eta_{\text {inv }}$ & $97 \%$ \\
Battery inverter efficiency & $\eta_{\text {bat }}$ & $94 \%$ \\
Battery charging efficiency & $\eta_{\text {cha }}$ & $90 \%$ \\
Battery discharging efficiency & $\eta_{\text {disc }}$ & $90 \%$ \\
Nominal battery voltage & $\mathrm{V}$ & $12 \mathrm{~V}$ \\
Sampling time interval & $\Delta \mathrm{t}$ & $1 \mathrm{hour}$ \\
Capital recovery factor & $\mathrm{CRF}$ & 0.1233 \\
Real interest rate & $\mathrm{i}$ & $4 \%$ per annum \\
Inverter lifetime & $\mathrm{N}$ & 10 years \\
Battery investment cost rate & & $\$ 200 / \mathrm{kWh}$ \\
\hline
\end{tabular}

When the load power is greater than PV power, it can describe as Netload. NetPV is describes as when the PV power is greater than Load power. The variables are defined in (1) and (2) [22-24].

$$
\begin{aligned}
& \operatorname{NetLoad}(d, t)=P_{\text {load }}(d, t)-P_{P V}(d, t) \\
& \operatorname{NetPV}(d, t)=P_{P V}(d, t)-P_{\text {load }}(d, t)
\end{aligned}
$$

To calculate the battery capacity loss cost per hour, it describes as in (3) [25]

$$
\mathrm{BCL}_{\text {cost }}(\mathrm{d}, \mathrm{t})=\frac{\mathrm{C}_{\text {loss }}(\mathrm{d}, \mathrm{t}) \times \mathrm{B}_{\text {invest }, \text { cost }}}{1-\mathrm{SOH}_{\min }}
$$

Where, $B C L_{\text {cost }}$ is the battery capacity loss cost $(\$), B_{\text {invest,cost }}$ is the battery investment cost $(\$ / \mathrm{kWh})$ and $\mathrm{SOH}_{\min }$ is the minimum state of health which considered as zero.

\section{RESULT}

The simulation results are taken separately from MATLAB for grid-connected PV with Lead Acid battery and Lithium-ion battery. The simulation runs in optimum energy flow with peak shaving. In this case, the main consideration is to reduce purchasing the energy from the utility grid during peak hour. This is because electrical tariff during peak hour is slightly higher than during off-peak hour.

\subsection{Lead acid Battery}

Figure 3 shows the energy flow schedule for lead acid battery. Energy flow schedule consist of E-pv,

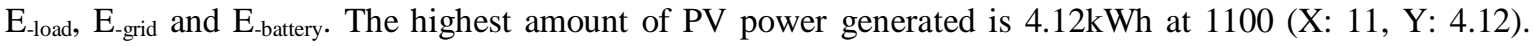
Sequence of activities for lead acid battery shown in Table 6.

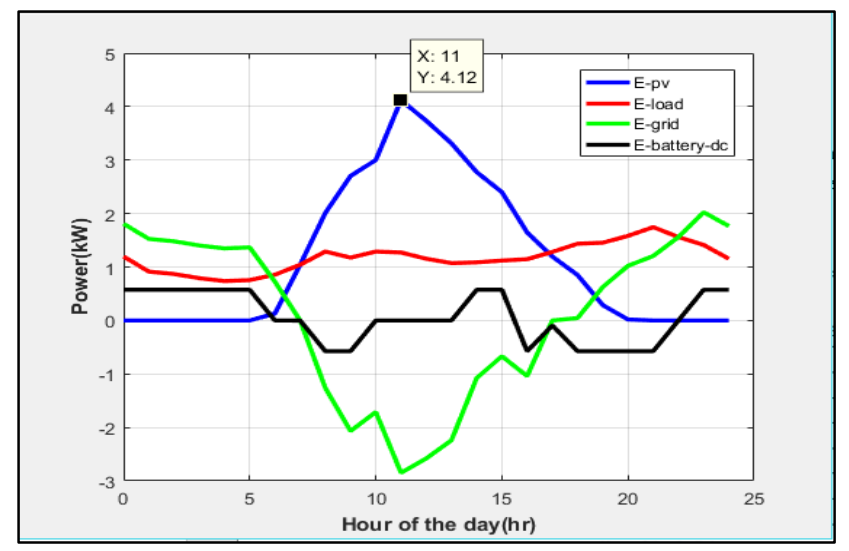

Figure 3. Energy transfer sequences of PV system 
Table 6. Sequence of Activities for Lead Acid Battery

\begin{tabular}{cc}
\hline Period & Activities \\
\hline $0000-0500$ & Energy from the grid is supplied to the load. \\
$0500-2000$ & PV starts to generate power from 0500 to 2000. \\
$0700-1700$ & The energy is sold to the utility grid during this period. The highest amount of energy has been sold is $2.848 \mathrm{~kW}$ at 1100. \\
1100 & The highest amount of PV power generated is $4.12 \mathrm{~kW}$. \\
$1100-2000$ & The PV power slightly decreasing until zero. \\
\hline
\end{tabular}

Figure 4 represent the optimum battery capacity with respect to minimum operating cost for lead-acid battery. Battery size with minimum operating cost is obtained after battery size is inserted into MATLAB program from 0Ah to 1500Ah. The selected battery capacity for Lead-Acid is 1200Ah with a cost of \$279.20.

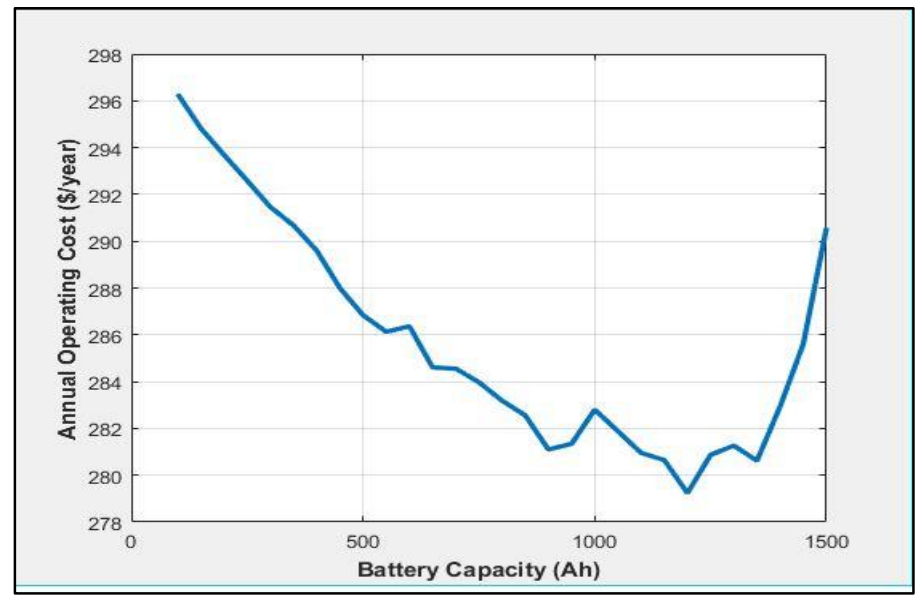

Figure 4. Optimum battery capacity with minimum operating cost

The expected calculated lifetime for this battery is 13 years. With that, the capital recovery factor (CRF) can be calculated by using [25]:

$$
C R F_{(i, N)}=\frac{i(1+i)^{n}}{i(1+i)^{n}-1}
$$

Where, $\mathrm{N}$ is the lifetime and i represent the interest rate. From that, the annualized battery cost can be obtained by using:

$$
\text { Annualised battery cost }=\text { battery capital cost } \times \mathrm{CRF}
$$

It can be seen Table 7, the annualized operating cost of PV system with lead acid battery is $\$ 346.85$. By using all related equations, the annual operating cost and profit by using lead acid battery inclusive the cost the inverter are:

Table 7. annual operating cost and profit for PV system with Lead Acid battery

\begin{tabular}{ccc}
\hline Operation cost/profit (per year) & Cost/profit (\$ per year) & Cost/profit after including CRF (\$ per year) \\
\hline Electricity profit & +48.74 & +48.74 \\
Cost of battery capacity loss & -220.39 & -288 \\
Inverter cost & -107.59 & -107.59 \\
Total (Annual operating cost) & -279.24 & -346.85 \\
\hline
\end{tabular}

\subsection{Li-ion Battery}

Figure 5 shows the energy flow schedule for Li-ion battery in the same system as before. The required energy to operate the load is supplied by utility grid during early hours of the day. The highest amount of PV power generated is $4.12 \mathrm{kWh}$ at 1100 hours. The activities for the energy transfer sequences of grid-connected PV system with a lithium-ion battery in particular hour as in Table 8. 


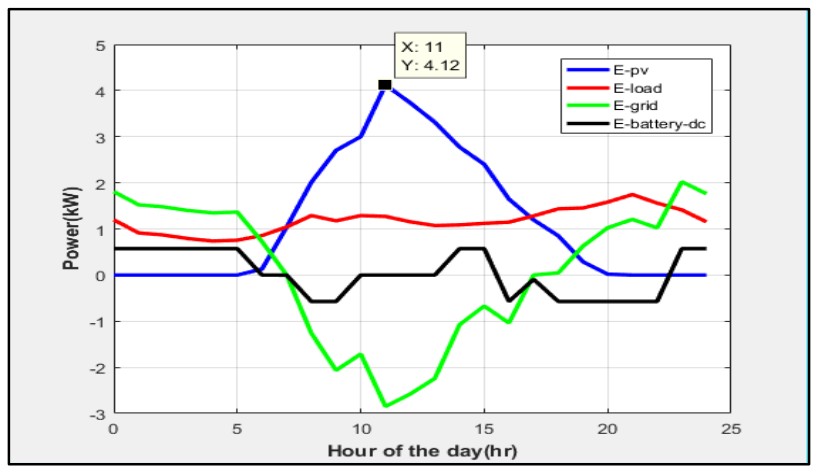

Figure 5. Energy transfer sequence of PV system

Table 8. Sequence of Activities for Li-ion battery

\begin{tabular}{cc}
\hline Period & Activities \\
\hline $0000-0700$ & Energy from the grid is supplied to the load. During this time, the battery is charging with maximum charging rate. \\
$0500-2000$ & PV starts to generates energy from 0500 until 2000 \\
$0700-1600$ & The energy is sold to the utility grid \\
1100 & The highest PV power generated $4.12 \mathrm{kWh}$ \\
2200 & The E-grid during this time is $1.022 \mathrm{~kW}$ \\
\hline
\end{tabular}

Figure 6 represent the optimum battery capacity with respect to minimum operating cost for Lithiumion battery. The selected battery capacity for Lithium-ion is 100Ah. The minimum annual operating cost is $\$ 353.1$ if the battery size is $100 \mathrm{Ah}(\mathrm{X}: 100, \mathrm{Y}: 353.1)$.

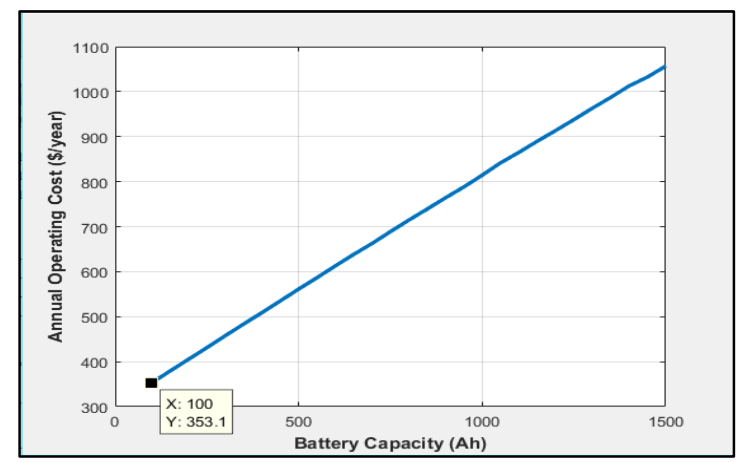

Figure 6. Optimum battery capacity with minimum operating cost

The annualized operating cost of PV system with Li-ion battery is $\$ 1471.24$. This can be seen as in Table 9. the battery lifetime estimation is 12 years.

Table 9. Annual Operating Cost and Profit for PV System with Li-ion Battery

\begin{tabular}{lcc}
\hline Operation cost/profit (per year) & Cost $(\$$ per year) & Cost after including CRF $(\$$ per year) \\
\hline Electricity profit & -265.042 & -265.042 \\
Cost of battery capacity loss & -79.0572 & -1197.3 \\
Inverter cost & -8.9557 & -8.9557 \\
Total (Annual operating cost) & -353.0721 & -1471.24 \\
\hline
\end{tabular}

\subsection{Comparison}

Based on the simulation with the same PV system and tariff, hence with different type of battery. The significant difference can be seen based on the total annual operating cost for both type of battery. The overall cost is tabulated in Table 10. 


\begin{tabular}{ccc} 
Table 10. Total Annual Operating Cost and Battery Capacity \\
\hline Operation cost / profit (per year) & Lead-Acid battery & Li-ion battery \\
\hline Electricity profit & $+\$ 48.74$ & $-\$ 265.042$ \\
Cost of battery capacity loss & $-\$ 288$ & $-\$ 1197.3$ \\
Inverter cost & $-\$ 107.59$ & $-\$ 8.9557$ \\
Total (Annual operating cost) & $-\$ 346.85$ & $-\$ 1471.24$ \\
\hline
\end{tabular}

\section{CONCLUSION}

The sizing of energy storage has been carried out by using two types of batteries which is Lead-acid battery and Lithium-ion battery. For both batteries, the same amount of PV output, similar load and same cost is used in the simulation. The manipulated variables for this simulation is the data for each type of batteries. As a result, there is a major difference of the minimum cost between the lead-acid battery and Li-ion battery. This can be seen in Table 10.

This project has achieved the objective by minimizing the cost of the consumers. The result is able to minimize the total cost of the operation. By comparing two types of energy storage, the ideal capacity value for both type of battery can be determined when the operational cost goes to its minimum. For leadacid battery, the capacity of battery selected is 1200Ah and the lifetime of the battery is approximately 13 years. While lithium-ion battery resulted as 100Ah and the lifetime of the battery is calculated as 12 years. The minimum annualised operating cost for lead-acid battery and lithium ion battery was analysed as $\$ 346.85$ and $\$ 1471.24$ respectively.

Since the selected capacity of Li-ion battery was literally small, the calculated cost of electricity is high unprofitable for the bills. When compared the electricity cost for both type of battery, the lead-acid battery resulted as $+\$ 48.74$, which is accepted. While the result for Li-ion is $-\$ 265.42$ which is the battery doesn't meet the objective for installing PV system to reduce the cost of electricity.

These results represented that, the total annualised minimum operating cost tremendously depends on the size of the battery and the investment cost of the energy. Therefore, by considering the minimum operating cost for both battery, this study can conclude that Lead-acid battery is more suitable to minimize the total annualised operating cost than Li-ion.

\section{ACKNOWLEDGEMENTS}

The authors gratefully acknowledge the support of the Universiti Teknikal Malaysia Melaka (UTeM) through Centre for Robotics and Industrial Automation (CeRIA) for the support. This research is financed through short term grant (PJP/2018/FKE(3A)/S01604) provided by the university.

\section{REFERENCES}

[1] REN21, Renewables 2018, Global Status Report, Paris, France.

[2] Vieira, F. M., Moura, P. S., \& de Almeida, A. T. (2017). Energy storage system for self-consumption of photovoltaic energy in residential zero energy buildings. Renewable Energy, 103, 308-320.

[3] Ramli, M. A., Hiendro, A., \& Twaha, S. (2015). Economic analysis of PV/diesel hybrid system with flywheel energy storage. Renewable Energy, 78, 398-405.

[4] Chong, L. W., Wong, Y. W., Rajkumar, R. K., \& Isa, D. (2016). An optimal control strategy for standalone PV system with Battery-Supercapacitor Hybrid Energy Storage System. Journal of Power Sources, 331, 553-565.

[5] Liu, J., Mei, C., Wang, H., Shao, W., \& Xiang, C. (2018). Powering an island system by renewable energy-A feasibility analysis in the Maldives. Applied Energy, 227, 18-27.

[6] Astaneh, M., Dufo-López, R., Roshandel, R., \& Bernal-Agustin, J. L. (2018). A novel lifetime prediction method for lithium-ion batteries in the case of stand-alone renewable energy systems. International Journal of Electrical Power \& Energy Systems, 103, 115-126.

[7] Fudholi, A. and Sopian, K., 2018. R\&D of photovoltaic thermal (PVT) systems: An overview. International Journal of Power Electronics and Drive Systems, 9(2), p.803.Linssen, J., Stenzel, P., \& Fleer, J. (2017). Techno-economic analysis of photovoltaic battery systems and the influence of different consumer load profiles. Applied Energy, 185, 2019-2025.

[8] Hesse, H., Schimpe, M., Kucevic, D., \& Jossen, A. (2017). Lithium-ion battery storage for the grid—A review of stationary battery storage system design tailored for applications in modern power grids. Energies, 10(12), 2107.

[9] Braun, M., Büdenbender, K., Magnor, D., \& Jossen, A. (2009, September). Photovoltaic self-consumption in Germany: using lithium-ion storage to increase self-consumed photovoltaic energy. In 24th European Photovoltaic Solar Energy Conference (PVSEC), Hamburg, Germany.

[10] Pan, W., Gao, W., \& Muljadi, E. (2009, April). The dynamic performance and effect of hybrid renewable power system with diesel/wind/PV/battery. In 2009 International Conference on Sustainable Power Generation and Supply (pp. 1-5). IEEE. 
[11] A.N. Azmi, Grid interaction performance evaluation of building-integrated photovoltaic system and analysis with energy storage on distributed network power management, Mar 2017, ISSN 1504-9272, ISBN 978-82-7117-848-2.

[12] Nawabjan, A., Iqbal, F. and Abdullah, A.S., 2018. A Front Surface Optimization Study for Photovoltaic Application. Telkomnika, 16(4), pp.1383-1387.Bonaccorso, F., Colombo, L., Yu, G., Stoller, M., Tozzini, V., Ferrari, A. C., \& Pellegrini, V. (2015). Graphene, related two-dimensional crystals, and hybrid systems for energy conversion and storage. Science, 347(6217), 1246501.

[13] Tsang, K. M., \& Chan, W. L. (2013). State of health detection for Lithium ion batteries in photovoltaic system. Energy conversion and management, 65, 7-12.

[14] Wolfs, P. (2010, December). An economic assessment of "second use" lithium-ion batteries for grid support. In 2010 20th Australasian Universities Power Engineering Conference(pp. 1-6). IEEE.

[15] Ayodele, T. R., Ogunjuyigbe, A. S. O., \& Olateju, B. E. (2018). Improving battery lifetime and reducing life cycle cost of a PV/battery system using supercapacitor for remote agricultural farm power application. Journal of Renewable and Sustainable Energy, 10(1), 013503.

[16] Hamedi, A. S., \& Rajabi-Ghahnavieh, A. (2016). Explicit degradation modelling in optimal lead-acid battery use for photovoltaic systems. IET Generation, Transmission \& Distribution, 10(4), 1098-1106.

[17] Merei, G., Moshövel, J., Magnor, D., \& Sauer, D. U. (2016). Optimization of self-consumption and technoeconomic analysis of PV-battery systems in commercial applications. Applied Energy, 168, 171-178.

[18] Diouf, B., \& Pode, R. (2015). Potential of lithium-ion batteries in renewable energy. Renewable Energy, 76, 375 380.

[19] Amrouche, S. O., Rekioua, D., Rekioua, T., \& Bacha, S. (2016). Overview of energy storage in renewable energy systems. International Journal of Hydrogen Energy, 41(45), 20914-20927.

[20] Ranaweera, I., \& Midtgård, O. M. (2016). Optimization of operational cost for a grid-supporting PV system with battery storage. Renewable Energy, 88, 262-272.

[21] Lan, H., Wen, S., Hong, Y. Y., David, C. Y., \& Zhang, L. (2015). Optimal sizing of hybrid PV/diesel/battery in ship power system. Applied energy, 158, 26-34.

[22] Mundada, A. S., Shah, K. K., \& Pearce, J. M. (2016). Levelized cost of electricity for solar photovoltaic, battery and cogen hybrid systems. Renewable and Sustainable Energy Reviews, 57, 692-703.

[23] Halabi, L. M., Mekhilef, S., Olatomiwa, L., \& Hazelton, J. (2017). Performance analysis of hybrid PV/diesel/battery system using HOMER: A case study Sabah, Malaysia. Energy Conversion and Management, 144, 322-339.

[24] Tsuanyo, D., Azoumah, Y., Aussel, D., \& Neveu, P. (2015). Modeling and optimization of batteryless hybrid PV (photovoltaic)/Diesel systems for off-grid applications. Energy, 86, 152-163.

[25] Bieri, M., Winter, K., Tay, S., Chua, A., \& Reindl, T. (2017). An irradiance-neutral view on the competitiveness of life-cycle cost of PV rooftop systems across cities. Energy Procedia, 130, 122-129.

\section{BIOGRAPHIES OF AUTHORS}

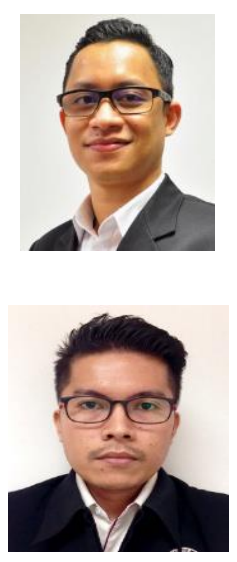

Aimie Nazmin Azmi received his B.Eng in electrical engineering (industrial power) from Univeristi Teknikal Malaysia Melaka, in 2006. He works at Intel Microelectronics (M) before pursue his study in M.Eng.Sc in energy system from The University of New South Wales, Sydney in 2010. He received his PhD in Renewable Energy from University of Agder, Norway in 2017. His research interest is in renewable energy, energy system and zero energy building (ZEB).

E-mail: aimienazmin@utem.edu.my

Norhafiz Bin Salim obtained his B.S. and M.S. from Universiti Teknikal Malaysia Melaka (UTeM), Malaysia and Universiti Teknologi Malaysia (UTM) in 2007 and 2009 respectively. He received his Dr. Eng. in Electrical Engineering from Yokohama National University (YNU), Japan, in 2017. He is currently a senior lecturer at UTeM. His research interests include the planning, operation and analysis of power systems.

E-mail: norhafiz@utem.edu.my

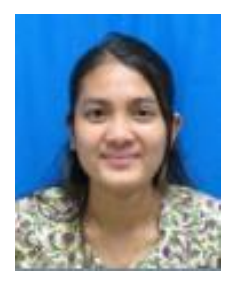

Aziah Bt Khamis obtained her BEng from Universiti Putra Malaysia (UPM) and MEng from Newcastle University, UK. Her PhD is from Universiti Kebangsaan Malaysia (UKM), where she works in Distribution Generation and Microgrid Energy System. She is also interested working on feature extractions and intelligent application of power system study.

E-mail: aziah@utem.edu.my 